\title{
DIAGNÓSTICO DAS ÁRVORES PATRIMONIAIS DE SANTA MARIA, RIO GRANDE DO SUL
}

\author{
DIAGNOSIS OF THE HERITAGE TREES OF SANTA MARIA, RIO GRANDE DO SUL
}

\author{
Jhonitan Matiello', Ana Paula Moreira Rovedder², Krissie Reckziegel ${ }^{3}$, Fabiane Granzotto ${ }^{4}$, \\ Luiz Geraldo Cervi ${ }^{5}$
}

\section{RESUMO}

O tombamento de árvores como patrimônio visa a proteção de indivíduos com importância histórica, cultural, ecológica ou científica. Objetivou-se analisar quali-quantitativamente o patrimônio vegetal tombado do município de Santa Maria-RS, e as alterações ao longo de 25 anos entre os únicos censos realizados, em 1989 e 2014. Analisaram-se número de indivíduos; origem das espécies; famílias botânicas; localização; ameaças; fenologia reprodutiva; dados dendrométricos e idade. O município tinha 106 árvores tombadas em 1989, com redução de 58,5\% em 2014. Quanto à origem, espécies nativas regionais sofreram a maior redução (27\%). Verificou-se a presença de duas espécies exóticas invasoras tombadas como árvores patrimoniais. As principais ameaças identificadas são pressão imobiliária, vandalismo e comprometimento da estrutura geral da árvore. Em média, 90\% dos indivíduos se localizam em áreas privadas nos dois censos e, em 2014, 80\% destes possuíam área livre ampla. Eventos fenológicos reprodutivos revelaram-se expressivos mesmo em condições adversas como fase senil dos indivíduos e ambiente urbano intensamente modificado. O patrimônio possui idade média de 61 anos, a última inclusão de indivíduos foi em 1983. Sugere-se a elaboração e aplicação de um plano de manejo, bem como a inclusão de novos indivíduos para dar sequência à existência do patrimônio.

Palavras-chave: Árvores urbanas; Ecologia urbana; Inventário censitário; Paisagismo; Planejamento urbano.

\begin{abstract}
Listing trees as heritage aims the protection of individuals with historical, cultural, ecological or scientific importance. The objective of this study was to quali-quantitatively analyze the heritage plants list of the municipality of Santa Maria-RS, and the changes over 25 years between the census carried out in 1989 and 2014. Data related to number of individuals; origin of species; botanical families; location; threats; reproductive phenology; dendrometric data and age were analyzed. The municipality had 106 heritage trees in 1989 , with reduction of $58.5 \%$ in 2014 . Regarding the origin, the regional native species suffered the largest reduction (27\%). Two invasive alien species were classified as heritage trees. The main threats identified are real estate pressure, vandalism and compromise of the tree's overall structure. On average, $90 \%$ of the individuals are located in private areas in both censuses, and in $2014,80 \%$ of them had a wide free area of development. Reproductive phenological events proved to be expressive even in adverse conditions such as senile phase of individuals and intensively modified urban environment. The average age of the heritage is 61 years old, the last inclusion of individuals was in 1983. It is suggested the elaboration and application of a management plan, as well as the inclusion of new individuals to follow the existence of the patrimony.
\end{abstract}

Keywords: Urban Trees; Census inventory; Landscaping; Urban ecology; Urban planning.

\footnotetext{
Recebido 09.03.2019 e aceito em 18.05.2019

${ }^{1}$ Engenheiro Florestal. Universidade Federal de Santa Maria. Santa Maria/RS. Email: jhonitan.matiello@yahoo.com.br

2 Engenheira Florestal. Professora Dra. na Universidade Federal de Santa Maria. Santa Maria/RS. Email: anarovedder@gmail.com

${ }^{3}$ Engenheira Florestal. Email: kris.kr@outlook.com

${ }^{4}$ Engenheira Florestal. Universidade Federal de Santa Maria. Santa Maria/RS. Email: fabianegranzotto@yahoo.com.br

${ }^{5}$ Engenheiro Florestal. Secretaria de Meio Ambiente de Santa Maria. Santa Maria/RS. Email: luizgeraldocervi@gmail.com
} 


\section{INTRODUÇÃO}

O espaço urbano, apesar de ser uma construção antrópica, não é exclusivamente humano. É paisagem de interações complexas entre diversos componentes bióticos e abióticos. Esses, por sua vez, influenciam e são influenciados pelo dinamismo desse ambiente.

Segundo dados da United Nations (2018) 55\% da população mundial vive nas cidades, estima-se que este número atinja $68 \%$ em 2050. Considerando a elevada concentração nestes espaços, Brandalise et al. (2019) frisam o papel da vegetação na saúde e bem-estar da população urbana, bem como na geração de serviços ecossistêmicos essenciais nestes ambientes extremamente modificados.

O aumento da pressão sobre os recursos naturais, o uso e ocupação irregular do solo geram cada vez mais consequências negativas sobre a paisagem urbana, principalmente nas áreas verdes que se encontram reduzidas, alteradas ou suprimidas (GRISE; BIONDI; ARAKI, 2016). Gonçalves e Meneguetti (2015) propõem que a compreensão da arborização urbana como patrimônio natural e cultural da cidade é essencial para estabelecer parâmetros e diretrizes para sua manutenção e preservação.

Uma forma de proteção do patrimônio consiste no seu tombamento, processo que compreende seu reconhecimento, inventário e catalogação. Henrique e Costa (2016) advertem para a importância da atuação de profissionais de diferentes áreas no processo de tombamento e conservação. Estes conceitos fundamentados basicamente em outras áreas, também se aplicam a árvores urbanas que, por apresentarem valor histórico, cultural, ecológico ou científico podem ser tombadas como patrimônio do município, do estado ou do país, de acordo com a abrangência de sua importância.

Nos trabalhos sobre o tema, principalmente em cidades brasileiras, verifica-se que os critérios de seleção de árvores para tombamento envolvem localização, raridade, beleza ou condição de porta sementes, antiguidade, referência para localização (SILVA JÚNIOR, 2010); sombra, porte significativo, espécie única, rara ou de interesse (DISALVO; DARLING, 2016). Na legislação florestal estadual do Rio Grande do Sul constam ainda o interesse cultural e/ou histórico e importância científica.

O tombamento de árvores como patrimônio é uma prática prevista na legislação, entretanto a base de literatura e conhecimento sobre o tema são escassos no Brasil, uma vez que a maior parcela dos estudos publicados possui foco em inventários quantitativos do patrimônio. Há, portanto, uma lacuna de trabalhos voltados à discussão de dados qualitativos de patrimônios vegetais tombados.

Visto isso, com o presente trabalho objetivou-se realizar um diagnóstico do patrimônio vegetal tombado do município de Santa Maria, Rio Grande do Sul. Com o estudo, pretende-se 
contribuir para a divulgação do patrimônio de árvores urbanas, tratar sobre aspectos técnicos a respeito do tombamento e principalmente subsidiar conhecimento para manutenção e melhorias no patrimônio.

\section{MATERIAL E MÉTODOS}

O município de Santa Maria localiza-se na região central do Rio Grande do Sul (Figura 1). A região se encontra em zona de tensão ecológica entre os Biomas Pampa e Mata Atlântica, com heterogeneidade ambiental e, consequentemente, grande biodiversidade de fauna e flora (ROVEDDER et al., 2014).

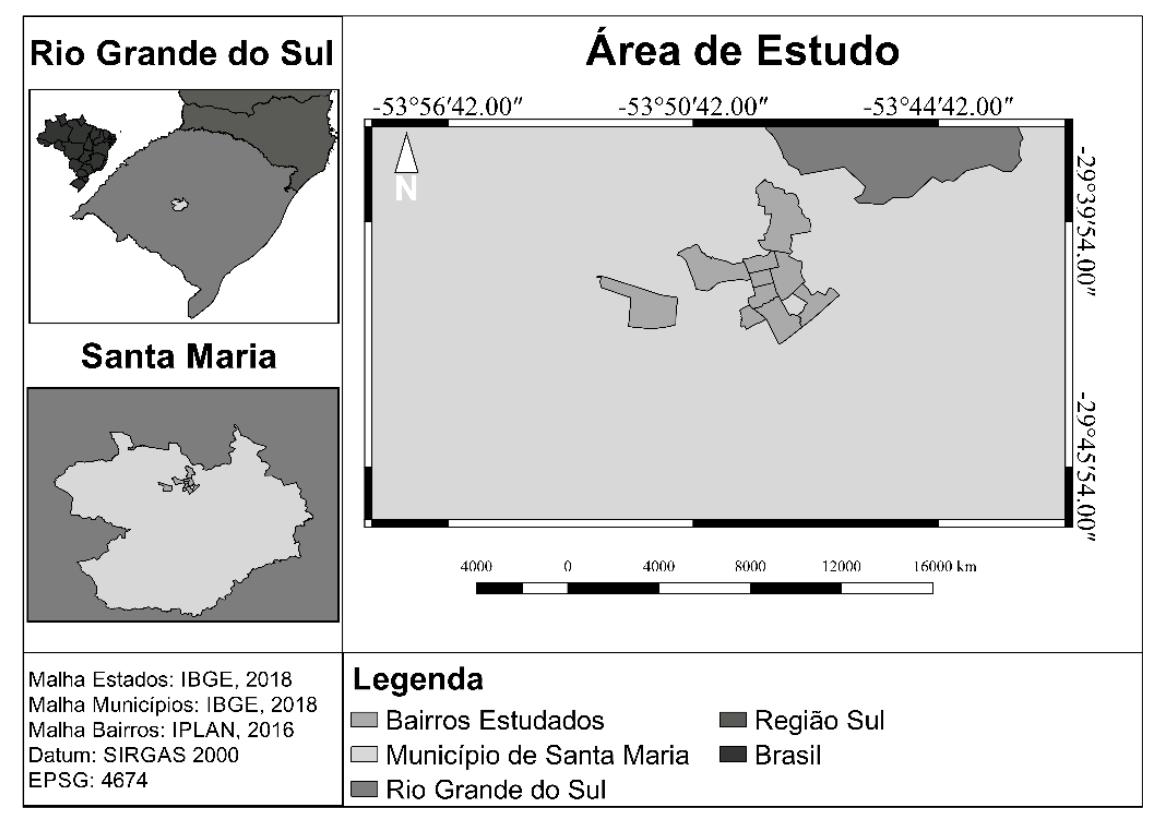

Figura 1. Localização da área de estudo

Figure 1. Location of the study area

O estudo foi realizado a partir dos dados de dois inventários do tipo censo do patrimônio vegetal tombado do município de Santa Maria. O primeiro levantamento, realizado pela equipe da Secretaria de Produção Agropecuária no ano de 1989, adotou uma ficha de avaliação adaptada, e publicada por Santos e Teixeira (1991).

Realizado pela equipe da Secretaria de Município de Meio Ambiente em 2014, o segundo censo seguiu a mesma ficha de avaliação, porém adaptada e atualizada, com inclusão de variáveis como coordenadas geográficas, categorias de origem, a situação atual e condição legal da árvore, floração e localização de acordo com a posse da propriedade.

Os dados coletados nos dois censos foram transferidos para uma planilha do software Microsoft Office Excelß (2016), para análise e extração de informações (Tabela 1). 
Tabela 1. Variáveis analisadas para os censos de 1989 e 2014

Table 1. Variables analyzed for the censuses of 1989 and 2014

\begin{tabular}{|c|c|}
\hline Variável & Descrição \\
\hline Espécie & Identificação em nível espécie \\
\hline Localização & $\begin{array}{l}\text { Área pública: caixa de passeio, praças e parques } \\
\text { Área privada: terrenos particulares }\end{array}$ \\
\hline Área livre & $\begin{array}{l}\text { Ampla: maior que } 5 \mathrm{~m}^{2} \\
\text { Regular: entre } 1,1 \mathrm{~m}^{2} \text { e } 5 \mathrm{~m}^{2} \\
\text { Restrita: menor que } 1 \mathrm{~m}^{2} \\
\text { Inexistente: pavimentação até a base do tronco }\end{array}$ \\
\hline Sistema radicular & $\begin{array}{l}\text { Profundo sem causar danos às calçadas e construções } \\
\text { Superficial sem causar danos às calçadas e construções } \\
\text { Superficial com danos às calçadas e construções }\end{array}$ \\
\hline Observações adicionais & $\begin{array}{l}\text { Escrita a punho qualquer informação sobre o indivíduo } \\
\text { considerada relevante pelo coletor }\end{array}$ \\
\hline Fenologia reprodutiva & $\begin{array}{l}\text { Presente } \\
\text { Ausente }\end{array}$ \\
\hline $\begin{array}{c}\text { Diâmetro da copa } \\
\begin{array}{c}\text { Circunferência na altura } \\
\text { do peito (CAP) }\end{array} \\
\text { Altura total }\end{array}$ & Metros \\
\hline Idade & Anos \\
\hline Processo de supressão & $\begin{array}{l}\text { Seguindo protocolo de destombamento, com emissão de parecer } \\
\text { técnico e alvará de supressão } \\
\text { Ilegal, não seguindo protocolo }\end{array}$ \\
\hline
\end{tabular}

As famílias botânicas das espécies foram atualizadas de acordo com o Angiosperm Phylogeny Group (APG IV, 2016). Nomes científicos e origem foram atualizados e confirmados conforme a "Lista de Espécies da Flora do Brasil 2020" (http://floradobrasil.jbrj.gov.br/reflora) e de acordo com o banco de dados nomenclatural científico Tropicos® (http://www.tropicos.org/).

Efetuou-se a classificação das espécies por meio de quatro categorias de origem, "nativa regional" (NR), "nativa do Brasil" (NB), "exótica não invasora" (ENI) e "exótica invasora" (El) adaptadas de Zardin et al. (2018).

$\mathrm{Na}$ categoria de árvores nativas regionais (NR) constam as espécies de ocorrência natural na região do estudo.

A categoria de espécies nativas do Brasil (NB) agrupou espécies que não ocorrem naturalmente na região, foram introduzidas de outras regiões do país e adaptaram-se às condições do ecossistema local.

A categoria de exóticas não invasoras (ENI) compreende espécies originárias de outros países e que não constam na Portaria 79/2013 que reconhece a lista de espécies exóticas invasoras para o Estado do Rio Grande do Sul (SEMA-RS, 2013).

A categoria de espécies exóticas invasoras (EI) agrupou espécies originárias de outros países e citadas no Anexo I da Portaria 79/2013 (SEMA-RS, 2013). 
As observações adicionais coletadas em ambos os censos serviram de dados-base para identificar e quantificar as ameaças ao patrimônio. As principais ameaças identificadas foram separadas aqui em sete categorias, sendo estas: comprometimento da estrutura geral da árvore, pressão imobiliária, presença de pragas, poda inadequada, raízes cortadas, vandalismo e árvores mortas - e fez-se a quantificação do número de indivíduos em cada uma destas categorias.

O comprometimento da estrutura geral foi verificado qualitativamente através da observação da presença ou ausência de fatores como o desequilíbrio da copa (verificado a partir da arquitetura comum da espécie em comparação com sua situação atual); copa formada pelo predomínio de brotações epicórmicas, árvore inclinada ou com altura de bifurcação abaixo de 1,80 metros.

Relacionou-se a pressão imobiliária com a supressão do indivíduo arbóreo para construção, a permanência da árvore isolada em meio a edificações ou sua mutilação por estarem próximas a obras posteriormente construídas.

A presença de pragas e parasitismo foi identificada pela presença de cupins na base do tronco, erva-de-passarinho (Struthanthus polyrhizus (Mart.) Mart., Struthanthus martianus Dettke \& Waechter e Tripodanthus acutifolius (Ruiz \& Pav.) Tiegh.) e figueira-mata-pau (Ficus americana Aubl.) nos ramos e fuste.

A poda inadequada foi identificada através da remoção assimétrica da copa ou redução excessiva de sua área, caracterizada como poda drástica por Martins et al. (2010). As raízes cortadas foram identificadas principalmente devido a presença de cortes e aterros para construções muito próximas às árvores quando da realização dos censos.

O vandalismo caracterizou-se pela observação de marcas de impacto, tronco descascado, anelado ou aterrado na base.

A fenologia reprodutiva foi avaliada pelo método visual como a metodologia proposta por Santos e Fisch (2013) em ambos os censos.

Obteve-se as médias para os dados de diâmetro da copa em metros, circunferência do tronco a 1,30 metros (CAP) em centímetros e altura total das árvores em metros, por inventário. Para o cálculo, foram desconsiderados dados discrepantes como indivíduos com redução drástica da altura por poda incorreta.

Quanto à idade das árvores patrimônio, para as que apresentaram essa informação, identificou-se a idade da árvore mais jovem e a idade da árvore mais velha a partir da data de transplantio. 


\section{RESULTADOS E DISCUSSÃO}

\section{Diagnóstico quantitativo}

Em 1989 existiam 106 árvores tombadas como patrimônio, distribuídas em 24 espécies de 11 famílias botânicas. Em 2014, restavam 44 árvores de 17 espécies e 10 famílias botânicas (Tabela 2). No período de 1989 - 2014 (25 anos) houve uma redução de 58,5\% no conjunto do patrimônio arbóreo tombado de Santa Maria.

Tabela 2. Lista de frequência de espécies do patrimônio vegetal tombado de Santa Maria, RS, nos censos de 1989 e 2014

Table 2. Species frequency list of the plant heritage of Santa Maria, RS, in the censuses of 1989 and 2014

\begin{tabular}{|c|c|c|c|c|}
\hline Nome científico & \multirow[t]{2}{*}{ Nome Popular } & \multirow[t]{2}{*}{ Orig. } & \multicolumn{2}{|c|}{$\begin{array}{c}\text { Freq. } \\
19892014\end{array}$} \\
\hline & & & & \\
\hline Araucaria angustifolia (Bert) (Bertol.) Kuntze & Araucária & NR & 16 & 5 \\
\hline \multicolumn{5}{|l|}{ Arecaceae } \\
\hline Syagrus romanzoffiana (Cham.) Glassman & Jerivá & NR & 8 & 6 \\
\hline \multicolumn{5}{|l|}{ Bignoniaceae } \\
\hline Handroanthus chrysotrichus (Mart. ex DC.) Mattos & Ipê-amarelo & NB & 1 & 0 \\
\hline Handroanthus heptaphyllus (Vell.) Mattos & Ipê-roxo & NR & 10 & 6 \\
\hline Jacaranda mimosifolia D. Don & Jacarandá & ENI & 7 & 2 \\
\hline \multicolumn{5}{|l|}{ Fabaceae } \\
\hline Delonix regia Bojer ex hook & Flamboyant & ENI & 5 & 4 \\
\hline Enterolobium contortisiliquum (Vell.) Morong & Timbaúva & NR & 16 & 1 \\
\hline Erythrina crista-galli $\mathrm{L}$. & Corticeira-do-banhado & NR & 2 & 2 \\
\hline Parapiptadenia rigida (Benth.) Brenan & Anqico-vermelho & NR & 4 & 3 \\
\hline Peltophorum dubium (Spreng.) Taub. & Canafístula & NB & 7 & 6 \\
\hline Schizolobium parahyba (Vell.) Blake & Guapuruvu & NB & 3 & 0 \\
\hline Tipuana tipu (Benth.) Kuntze & Tipuana & $\mathrm{El}$ & 1 & 1 \\
\hline \multicolumn{5}{|l|}{ Fagaceae } \\
\hline Quercus robur $\mathrm{L}$. & Carvalho & ENI & 1 & 0 \\
\hline \multicolumn{5}{|l|}{ Malvaceae } \\
\hline Ceiba speciosa (A.St.-Hil.) Ravenna & Paineira & NB & 5 & 2 \\
\hline Luehea divaricata Mart. \& Zucc. & Açoita-cavalo & NR & 2 & 1 \\
\hline \multicolumn{5}{|l|}{ Meliaceae } \\
\hline Cedrela fissilis Vell. & Cedro & NR & 5 & 1 \\
\hline \multicolumn{5}{|l|}{ Myrtaceae } \\
\hline Campomanesia xanthocarpa (Mart.) O.Berg & Guabirobeira & NR & 1 & 0 \\
\hline Myrcianthes pungens (O. Berg) D.Legrand & Guabijuzeiro & NR & 1 & 0 \\
\hline Plinia cauliflora (DC.) Kausel & Jaboticabeira & NB & 1 & 1 \\
\hline Psidium cattleianum Sabine & Araçazeiro & NR & 1 & 1 \\
\hline \multicolumn{5}{|l|}{ Proteaceae } \\
\hline Grevillea robusta A. Cunn. ex. R. Br. & Grevílea & ENI & 1 & 1 \\
\hline \multicolumn{5}{|l|}{ Rhamnaceae } \\
\hline Hovenia dulcis Thunb. & Uva-do-japão & $\mathrm{El}$ & 3 & 1 \\
\hline \multicolumn{5}{|l|}{ Salicaceae } \\
\hline Salix babylonica $\mathrm{L}$. & Salso-chorão & ENI & 2 & 0 \\
\hline Salix humboldtiana Willd. & Salseiro & NR & 3 & 0 \\
\hline Total & & & 106 & 44 \\
\hline
\end{tabular}


Os resultados quanto à origem das espécies demonstraram que existe um baixo número de espécies na categoria de exóticas não invasoras (ENI), sendo cinco espécies em 1989 e apenas três em 2014. Jacaranda mimosifolia foi a mais frequente, com sete indivíduos dos 16 para esta categoria.

A presença de espécies exóticas invasoras no patrimônio reflete a escassez ou até mesmo inexistência de tal conhecimento para a seleção das espécies. Na época de criação do patrimônio (1982-1983), o problema da invasão biológica não era expressivo no Estado do RS, entretanto atualmente consiste em uma problemática grave e que merece atenção no planejamento urbano. Segundo Barros et al. (2018), a presença de espécies exóticas na arborização urbana é resultado da falta de organização técnica, de planejamento e de conhecimento da legislação ambiental. Portanto, o debate sobre o impacto destas espécies nos ecossistemas naturais assumiu protagonismo na última década.

A categoria de espécies exóticas invasoras (EI) foi composta por Hovenia dulcis e Tipuana tipu. Apesar de não ser considerada uma espécie exótica invasora agressiva, de acordo com a Portaria n. 79/2013 da SEMA o emprego de Tipuana tipu deve ser evitado, podendo ser cultivada sob restrições e manejo controlado, sendo classificada como categoria 2 pela mesma Portaria. Já a espécie Hovenia dulcis é classificada como categoria 1, por ser uma espécie exótica invasora de comportamento agressivo, é proibido o transporte, propagação e cultivo sob qualquer forma, representando grande ameaça aos ecossistemas naturais.

Considerando a rica diversidade de espécies nativas brasileiras e a significativa parcela que possui potencial para arborização urbana e cultivo nas condições de Santa Maria, a categoria de espécies nativas do Brasil (NB) apresenta um número pequeno de espécies, cinco em 1989, sendo reduzido a três até 2014. Schizolobium parahyba e Handroanthus chrysotrichus não possuem mais representantes tombados. Peltophorum dubium apresentou o maior número de indivíduos tombados nesta categoria (sete), seguido por Ceiba speciosa (cinco).

A categoria de espécies nativas regionais (NR) em 1989 representava 65\% do patrimônio, composta por 69 indivíduos distribuídos em 12 espécies. Com maior frequência se destacavam Enterolobium contortisiliquum (16), Araucaria angustifolia (16), Handroanthus heptaphyllus (dez) e Syagrus romanzoffiana (oito). Esta foi a classe de espécies que sofreu maior redução da frequência até o último censo, em que restaram apenas nove espécies e 26 indivíduos. Campomanesia xanthocarpa, Myrcianthes pungens e Salix humboldtiana sofreram supressão total entre os inventários.

Do ano de 1989 para o ano de 2014, verificou-se uma redução em todas as categorias de origem das espécies. Mesmo com a drástica redução de $62,3 \%$ no número de árvores nativas regionais tombadas como patrimônio, esta categoria manteve-se a maior em número de espécies ao longo do tempo (Figura 2). 


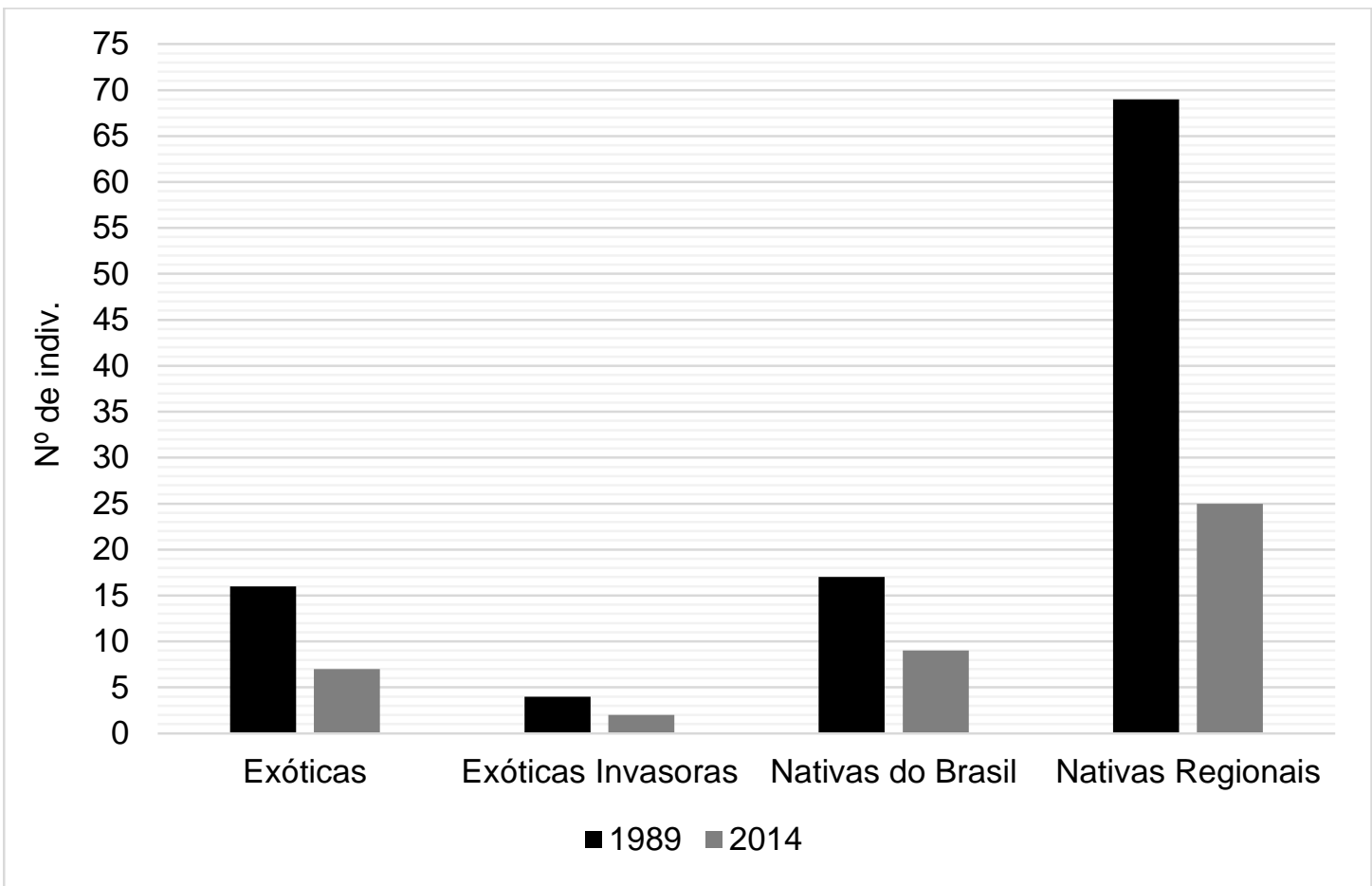

Figura 2. Número de indivíduos por categoria de espécies nos dois censos do patrimônio vegetal tombado de Santa Maria, RS

Figure 2. Number of individuals per category of species in the two censuses of the heritage-listed plants of Santa Maria, RS

As espécies nativas regionais apresentam papel fundamental na dinâmica do ecossistema local e prestam importantes serviços ecossistêmicos no meio urbano. A elevada redução do número de espécies e de indivíduos ou sua total supressão retratam um aspecto negativo para a conservação da biodiversidade regional no meio urbano, esta que é um dos objetivos do tombamento como patrimônio.

As famílias com maior número de espécies foram Fabaceae e Bignoniaceae, entretanto também sofreram a maior redução do número de indivíduos juntas perderam 31 indivíduos no intervalo de 25 anos. A família Fabaceae continha sete espécies em 1989 e reduziu para seis até 2014. Bignoniaceae continha três espécies em 1989 e reduziu para duas até 2014.

Entre 1989 e 2014, 11 indivíduos da família Araucariaceae foram suprimidos. Considerando a importância cultural e ecológica que a Araucaria angustifolia possui, principalmente pela região estar ao limite sul da ocorrência da espécie, este dado representa uma importante perda para o patrimônio. Assim como na família Salicaceae em que sua espécie representante nativa regional Salix humboldtiana também foi suprimida completamente no intervalo de 25 anos (Figura 3). 


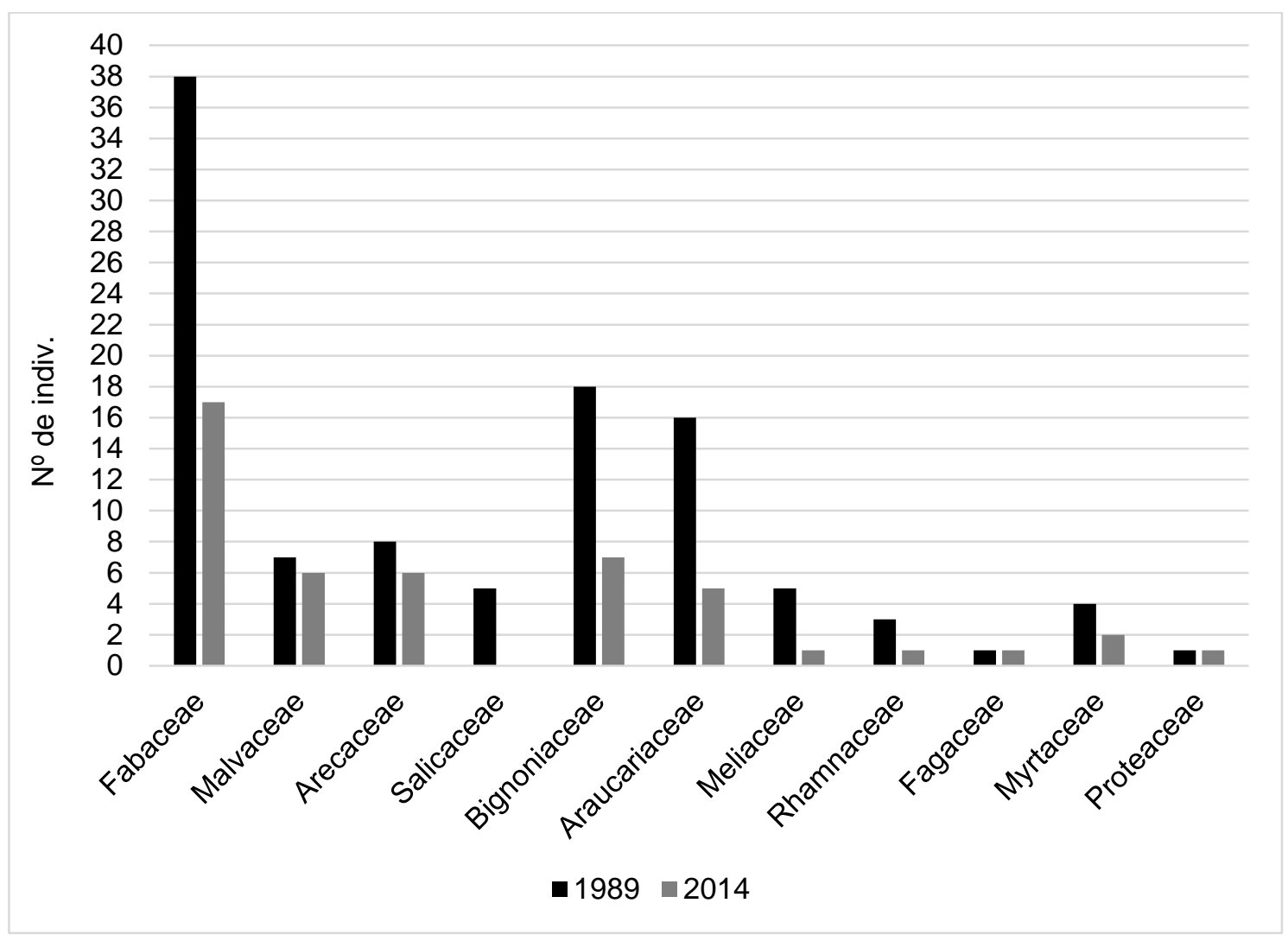

Figura 3. Número de indivíduos por família nos censos de 1989 e 2014

Figure 3. Number of individuals per family in the censuses of 1989 and 2014

Segundo Bobrowski e Biondi (2015), a baixa diversidade de espécies na arborização urbana é um gargalo frequente nas cidades brasileiras. Jim (2005) ao avaliar o Impacto de Contribuição na Paisagem (sigla LIC em inglês) da parcela da arborização urbana tombada como patrimônio de Guangzhou, verificou que uma escolha mais ampla de espécies poderia contribuir para redução dos impactos externos sobre o patrimônio.

\section{Diagnóstico qualitativo}

Quanto à localização do patrimônio remanescente, em 2014, 54\% das árvores possuíam área livre ampla, 19\% área livre regular e 16\% área livre restrita. Contudo, nenhuma árvore apresentava conflitos do sistema radicular com estruturas construídas. Cabe ressaltar que alguns dados podem sofrer o efeito da temporalidade, de maneira que no tempo entre avaliações, o fenômeno da intensa dinâmica de alteração da ocupação do solo urbano, também verificado por Brandalise et al. (2019), pode dificultar a observação integral dos acontecimentos. Entretanto, ao analisar os dois censos obtêm-se conhecimento da situação inicial e, gera-se informações sobre a situação final em que se encontram as árvores. 
Nos dois censos, em média 90\% dos indivíduos estava em propriedade privada, tipicamente representada por jardins com ampla superfície permeável. Verificou-se que, em 2014, 80\% das árvores que possuíam área livre ampla localizavam-se em propriedade privada.

Dados sobre o processo de supressão demonstraram que $42 \%$ do total de árvores patrimoniais foram suprimidas ilegalmente ao longo dos 25 anos, enquanto apenas 11,6\% ocorreram dentro do processo legal que envolve o destombamento por meio de lei municipal seguido de parecer técnico e alvará de supressão emitidos pelo órgão licenciador municipal. Atribuiu-se o baixo percentual de cumprimento ao protocolo principalmente devido ao tempo de duração e da abertura do processo de destombamento e supressão tardiamente por parte da população.

Em 1989, 27 indivíduos (25,5\% do total) se encontravam em terrenos de instituições privadas como colégios e conventos, já no segundo censo este número reduziu para 15 indivíduos (34\% do total remanescente). Ressalta-se que todas estas supressões foram efetuadas dentro do protocolo de destombamento e supressão, logo pode-se associar diretamente a localização da árvore patrimonial com o cumprimento legal de manutenção e supressão do patrimônio.

Os resultados para eventos fenológicos reprodutivos revelaram-se expressivos, sendo encontradas 58\% de árvores em frutificação ou floração em 1989 e 73\% em 2014. Relaciona-se estes índices ao período de avaliação que, nos dois censos, correspondeu aos meses finais do inverno e início da primavera, ápice da fenologia reprodutiva de plantas de dias longos. É evidenciada também a capacidade das árvores expressarem sua fenologia reprodutiva sob constante estresse do ambiente urbano, representando a vitalidade dos indivíduos.

Quanto à idade do patrimônio, verificou-se que em 2014 a árvore mais jovem possuía 31 anos e a mais velha 91 anos, sendo a idade média 61 anos. Portanto, considerando-se os anos cujo patrimônio foi tombado (1982 e 1983), não foram incluídas mais árvores após a sua criação. Os dados de diâmetro médio da copa, CAP médio e altura média foram 28,6 metros, 2,04 metros e 14,6 metros, respectivamente, evidenciando o grande porte e a idade avançada das árvores patrimoniais.

Segundo Jim (2017), a senescência do conjunto de árvores patrimoniais exige a inclusão de sucessores jovens para sustentar o patrimônio ao longo das gerações, o que raramente faz parte da realidade das cidades brasileiras. Este autor complementa que, sempre que possível, os conflitos devem ser resolvidos pela preservação in situ das árvores.

Com relação às ameaças ao patrimônio remanescente, verificou-se que 17 indivíduos $(38 \%)$ se encaixaram em pelo menos uma categoria de ameaça (Figura 4). 


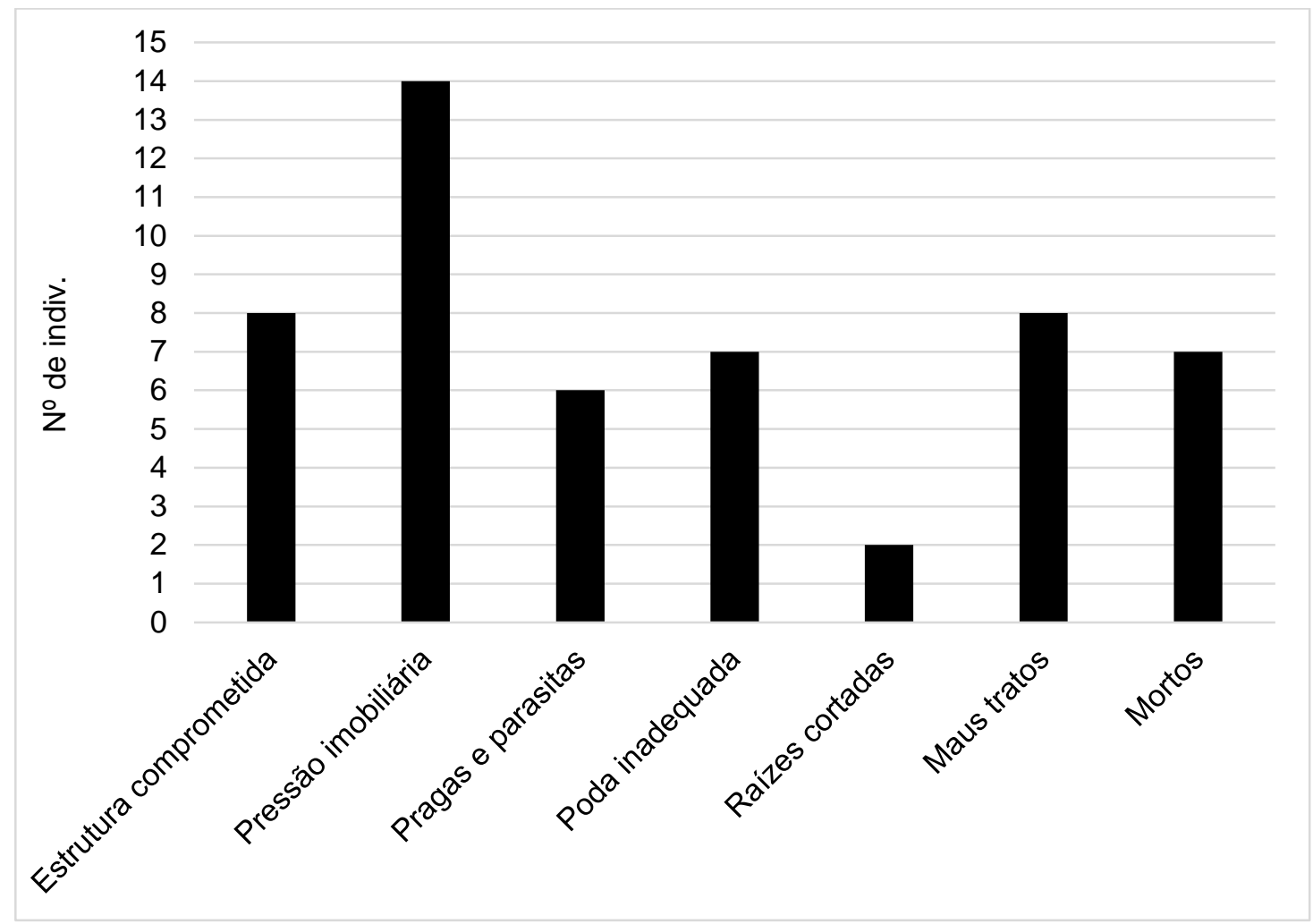

Figura 4. Número de indivíduos por categorias de problemas que comprometem o estado das árvores e número de indivíduos mortos

Figure 4. Number of individuals per categories of problems that compromise the condition of trees and number of dead individuals

Constatou-se que a pressão imobiliária, vandalismo, estrutura comprometida, raízes cortadas, poda inadequada são ameaças decorrentes do frequente caráter de impedimento à construção civil que a vegetação em terrenos livres assume.

A presença de doenças e pragas e a estrutura comprometida das árvores reflete a carência de órgãos de manutenção do patrimônio tombado, assim como verificam De Angelis e De Angelis Neto (2004) e Jim (2005). Neste caso, as árvores patrimoniais são exigentes em manejo, diferente do comumente empregado na arborização urbana. Além da carência de órgãos de manutenção, verifica-se também o manejo inadequado por falta de conhecimento técnico dos executores das intervenções.

\section{CONCLUSÕES}

As categorias de ameaças, principalmente a pressão imobiliária, o vandalismo, a presença de espécies exóticas invasoras e o alto número de supressões fora do protocolo legal refletem a necessidade de medidas emergenciais para conter a depreciação e a redução do patrimônio arbóreo do município de Santa Maria - RS. 
A elevada redução de árvores tombadas sinaliza a importância da inclusão de novos indivíduos no patrimônio, o que deve ser uma atividade multidisciplinar e com participação da sociedade local.

Portanto, o conhecimento e a divulgação das árvores patrimoniais são valorosos ao município porque servem de base para elaboração e aplicação de planos de manejo para este tipo de patrimônio.

\section{AGRADECIMENTOS}

À Prefeitura Municipal de Santa Maria por meio da Secretaria de Município de Meio Ambiente pelo acesso aos dados e à equipe de estagiários que auxiliaram no censo de 2014 , Karina Wolf e Frederico Neuenschwander.

\section{REFERÊNCIAS}

ANGIOSPERM PHYLOGENY GROUP IV. An update of the Angiosperm Phylogeny Group classification for the orders and families of flowering plants. Botanical Journal of the Linnean Society, Oxford, v. 181, n. 1, p. 1- 20, 2016.

BARROS, V. S.; MARTINS, C. M.; SANTOS, M. A. S.; REBELLO, F. K.; MONTEIRO, C. W. B.; MESQUITA, I, S. B. Avaliação da organização Arbórea e a percepção dos usuários das praças do município de Mocajuba, estado do Pará, Brasil. Revista da Sociedade Brasileira de Arborização Urbana, Curitiba, v.13, n.3, p. 01-12, 2018.

BOBROWSKI, R.; BIONDI, D. Influência das espécies exóticas invasoras na expressão da diversidade da arborização de ruas de Curitiba-PR. Revista da Sociedade Brasileira de Arborização Urbana, Curitiba, v. 10, n. 2, p. 27-39, 2015.

BRANDALISE, M.; PRANDEL, J.; QUADROS, F.; ROVANI, I.; MALYSZ, M.; DECIAN, V. Influence of Urbanization on the Dynamics of the Urban Vegetation Coverage Index (VCI) in Erechim (RS). Floresta e Ambiente, Rio de Janeiro, v. 26, n. 2, p. 1-9, 2019.

DE ANGELIS, B. L. D.; DE ANGELIS NETO, G. Jardins Históricos: introduzindo a questão. In: Paisagem e Ambiente. São Paulo, n.19, p. 31-48, 2004.

DISALVO, A.; DARLING, J. Heritage Tree Program Guidebook. Portland, Portland Parks \& Recreation, 2016.

GONÇALVES, A.; MENEGUETTI, K. S. Projeto de arborização como patrimônio da cidade. Ambiente Construído, Porto Alegre, vol. 15, n. 1, p. 99-118, 2015. 
GRISE, M. M.; BIONDI, D.; ARAKI, H. Distribuição Espacial e Cobertura de Vegetação das Tipologias de Áreas Verdes de Curitiba, PR. Floresta e Ambiente, Rio de Janeiro, vol.23, n.4, p. 498-510, 2016.

HENRIQUE, G. M. N.; COSTA, A. G. Considerações e propostas para a política de conservação de materiais pétreos do patrimônio construído no Brasil. Geonomos, Minas Gerais, v. 24, n. 2, p. 111-116, 2016.

JIM, C. Y. Outstanding remnants of nature in compact cities: patterns and preservation of heritage trees in Guangzhou city (China). In: Geoforum, Milão, vol. 33, n. 3, p. 371-385, 2005.

JIM, C. Y. Urban Heritage Trees: Natural-Cultural Significance Informing Management and Conservation. In: TAN, P.; JIM, C. Y. Greening Cities: Forms and Functions (Advances in t21st Century Human Settlements). Springer: Singapore; 2017. 394p.

MARTINS, L. F. V.; ANDRADE, H. H. B.; DE ANGELIS, B. L. D. Relação entre podas e aspectos fitossanitários em árvores urbanas na cidade de Luiziana, Paraná. Revista da Sociedade Brasileira de Arborização Urbana, Curitiba, v.5, n.4, p. 141-155, 2010.

ROVEDDER, A. P. M.; ALMEIDA, C. M.; ARAUJO, M. M.; TONETTO, T. S.; SCOTTI, M. S. V. Relação solo-vegetação em remanescente da Floresta Estacional Decidual na Região Central do Rio Grande do Sul. Ciência Rural, Santa Maria, v. 44, n. 12, p. 2178-2185, 2014.

SANTOS, C. H. V.; FISCH, S. T. V. Fenologia de espécies arbórea em região urbana, Taubaté, SP. Revista da Sociedade Brasileira de Arborização Urbana, Curitiba, v.8, n.3, p. 01-17, 2013.

SANTOS, M. R. Z. dos; TEIXEIRA, I. F. Levantamento das espécies imunes ao corte no município de Santa Maria - RS. Santa Maria: Edições UFSM, 1991. 324p.

SECRETARIA DE MEIO AMBIENTE E DESENVOLVIMENTO SUSTENTÁVEL DO RS.

Portaria n. 79 de 31 de outubro de 2013. Diário Oficial do Estado, Rio Grande do Sul, RS, 01 nov. 2013.

SILVA JÚNIOR, L. F. da. A jurema tombada: memórias de uma experiência religiosa. In: $\mathbf{X}$ Encontro Nacional de História Oral - Testemunhos: História e política. Pernambuco, 2010.

UNITED NATIONS, World Urbanization Prospects: The 2018 revision. Key Facts. Disponível em: <https://population.un.org/wup/Publications/Files/WUP2018-KeyFacts.pdf>. Acesso em: 22 jan. 2019.

ZARDIN, M. C.; BIONDI, D.; LEAL, L.; OLIVEIRA J. D.; MARIA, T. R. B. C. Avaliação qualiquantitativa da arborização viária do município de Augusto Pestana-RS. Revista da Sociedade Brasileira de Arborização Urbana, Curitiba, v. 13, n. 3, p. 36-48, 2018. 